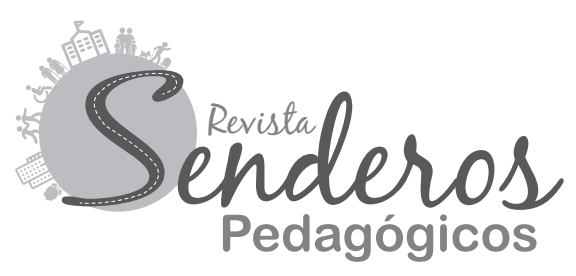

\title{
Experiencia digital en la enseñanza del Ch'ol en Chiapas, México ${ }^{1}$
}

\section{Digital experience in teaching Ch'ol in Chiapas, Mexico}

\author{
Autores: \\ Oscar Montejo Cruz ${ }^{2}$ \\ José Bastiani Gómez ${ }^{3}$ \\ Segundo Jordán Orantes Alborez ${ }^{4}$ \\ Recibido: 10/10/2019 \\ Aprobado: 02/12/2019
}

1. Resultado parcial de investigación realizado en el marco del desarrollo del proyecto denominado: El diseño tecnopedagógico de un objeto digital para la enseñanza y aprendizaje del Ch'ol en la Universidad Intercultural de Chiapas, que se efectuó en el marco de los estudios de Maestría en Didáctica de las Lenguas en la Facultad de Lenguas de la Universidad Autónoma de Chiapas. El posgrado se encuentra inscrito en el Programa Nacional de Posgrados de Calidad (PNPC) del Consejo Nacional de Ciencia y Tecnología de México (CONACyT) a través del cual se tuvo acceso a la beca No. 861041 que permitió la realización en el periodo que comprendió del año 2018 a 2019 en la región de los Altos de Chiapas, México.

2. Ingeniero en Sistemas Computacionales por el Instituto de Estudios Superiores de Chiapas Salazar Narváez. Licenciado en Educación Primaria para el Medio Indígena por la Universidad Pedagógica Nacional, Unidad 071, Subsede San Cristóbal de Las Casas, Chiapas. Maestrante en Didáctica de las Lenguas por la Universidad Autónoma de Chiapas, México.

montecruz.racso@gmail.com

3. Licenciado en Sociología por la Universidad Juárez de Tabasco. Magíster en Educación Indígena por la Universidad Autónoma de Chiapas y Doctor en Ciencias en Ecología y Desarrollo Sustentable por el Colegio de la Frontera Sur, Chiapas, México. bastianijose14@hotmail.com

4. Doctor en Educación y Profesor-Investigador en la Universidad de Ciencias y Artes de Chiapas (UNICACH). Colabora como asesor académico en el Programa de Maestría en Educación y Diversidad Cultural y Maestría en Educación Básica, en la Universidad Pedagógica Nacional, Unidad o71, Tuxtla Gutiérrez, Chiapas; México. jordan.orantes@unicach.mx

\section{Resumen}

El trabajo aborda la construcción de un objeto digital para la enseñanza de la lengua Ch'ol con estudiantes de la Universidad Intercultural de Chiapas, en San Cristóbal de Las Casas, Chiapas. La investigación tiene fundamento cualitativo porque considera el objeto de estudio de forma interpretativa y holística en los procesos educativos digitales. La aplicación de entrevista semiestructurada, el diario de campo y la observación participante permitieron recabar información que evidencia el desarrollo de un recurso digital en el aprendizaje de la lengua originaria con pertinencia y eficacia en la educación superior. Además, se obtuvo que la tecnología permite la interacción autónoma y fortalece la comunicación entre estudiantes y profesores en el aula. Por último, se sugiere construir una política de educación intercultural digital que se articule con las demandas de la sociedad del conocimiento para el fortalecimiento de la identidad lingüística y cultural de los estudiantes universitarios, en Chiapas. 
Palabras clave: competencias, educación intercultural, lengua materna, lingüística, tecnología.

\begin{abstract}
The work deals with the construction of a digital object for teaching the Ch'ol language with students from the Intercultural University of Chiapas, in San Cristóbal de Las Casas, Chiapas. The research has a qualitative basis because it considers the object of study interpretively and holistically in digital educational processes. The semistructured interview application, the field diary and the participant observation allowed to gather information that
\end{abstract}

evidenced the development of a digital resource in the learning of the original language with relevance and efficiency in higher education. In addition, it was obtained that technology allows autonomous interaction and strengthens communication between students and teachers in the classroom. Finally, it is suggested to build a digital intercultural education policy that articulates with the demands of the knowledge society for the strengthening of the linguistic and cultural identity of university students, in Chiapas.

Keywords: Skills, intercultural education, mother tongue, linguistics, technology.

\section{Introducción}

La política lingüística y educativa en México, desde la década de los noventa del siglo XX a la fecha, hace hincapié en que la universidad debe contribuir a la preservación y el fortalecimiento de las lenguas originarias del país. Es por ello, que dicha política ha focalizado su cometido en elevar el número de población, en edad escolar, para ingresar a la educación superior. En este sentido, la Ley de Derechos Lingüísticos de los Pueblos Indígenas ${ }^{5}$ del año 2003 ha fortalecido dicha concepción y ha permitido un largo proceso de visibilización de los estudiantes indígenas, para que puedan ingresar y formarse en el nivel superior con identidades y lenguas propias. Por esta razón, las universidades interculturales surgidas desde el año 2001 en México, deben asumir el reto de promover una educación superior en y para los estudiantes que provienen de las regiones indígenas de México y de Chiapas (Fábregas, 2008; Aguirre, 2015). De igual modo, la formación universitaria también debe ser encauzada a partir del dominio de competencias digitales, como parte de los procesos de integración global y de tecnología, para abatir el rezago en el uso de los medios de comunicación digital. De tal manera, que la educación digital constituye una prioridad en la sociedad del conocimiento o digitalizada e interconectada de múltiples modos de comunicación (Castells, 2000).

5 La citada ley es un componente legal que centra su acción en el reconocimiento de los derechos, tanto individuales, como colectivos de las lenguas originarias de México; misma que encuentra su base en la Declaración Universal de Derechos Lingüísticos. 
Es de reconocer que las virtudes del uso de la tecnología en la actualidad han sido una oportunidad para socializar los conocimientos ancestrales, la cosmovisión y diversas concepciones del mundo que tienen los pueblos originarios. Al respecto, Hernández y Calcagno (2003) señalan que el acceso y dominio de competencias digitales, contribuyen a que los pueblos originarios puedan trascender el nivel local y alcanzar presencia regional, nacional e internacional como parte de la integración global. También aducen que la tecnología digital permite fortalecer y potenciar diversos procesos político-organizativos, de comunicación, revitalización lingüística y cultural en el mundo contemporáneo. Estudios recientes (Sunkel, Trucco y Espejo, 2014a; Barreto y Diazgranados, 2017) señalan que es una ventaja el uso de las TIC en diversos ámbitos de la vida social y educativa, ya que contribuyen a acortar la distancia geográfica entre ciudades y zonas rurales, países y continentes, y favorecen el acceso a la información, al conocimiento y la formación de los estudiantes indígenas y no indígenas, como ocurre en la Universidad Intercultural de Chiapas (UNICH).

En las aulas universitarias de la UNICH prevalecen lo que se denominan nativos digitales según Fajardo, Villalta y Salmerón (2016); es decir, los jóvenes hablantes de las lenguas Tseltal, Ch'ol, ${ }^{6}$ Tsotsil y Zoque que desde su nacimiento se han involucrado en el uso de diversos dispositivos tecnológicos como laptops, tabletas, iPads, Smartphone, entre otros aparatos electrónicos que están modificando la cultura identitaria y educativa. Esta habilidad digital se aprovecha para el beneficio del proceso de aprendizaje y enseñanza, que bajo el modelo intercultural se señala como una condición normativa: construir el conocimiento escolar y digital en la era global (Ianni, 2006; Castellanos, 2014).

Es importante notar que, a través del tiempo, se han generado diversos materiales educativos digitales e impresos para alumnos y docentes, dirigidos a un contexto específico cultural. En el caso de la lengua Ch'ol aún es limitado, los recursos existentes son elaborados por docentes hablantes nativos; las acciones que se han implementado son de carácter lingüístico como la elaboración de la normalización de escritura de la lengua Ch'ol (INALI, 2011a); ña'alty'añ Ch'ol (gramática descriptiva) (Montejo, López, Guzmán, Jiménez y Martínez, 1999); vocabulario Ch'ol-español (López y Gutiérrez, 2002); säkläji’b ty'añ Ch'ol (diccionario de la lengua Ch'ol) (Jiménez y Gutiérrez, 2008); libros de texto para alumnos a partir de la lexicología (Cruz, 2009). Además, las producciones del Instituto Lingüístico

6 La lengua Ch'ol es hablada en el norte del estado de Chiapas, en los municipios de Huitiupan, Sabanilla, Tila, Tumbalá, Salto de Agua y Palenque. Debido a la migración actualmente se han dispersado en otras localidades y Estados de la República, incluso al extranjero. El total de hablantes de esta lengua según datos del Instituto Nacional de Estadística y Geografía recogido en el año 2015 es de 251809 de tres años en adelante. 
de Verano ${ }^{7}$ incentivan el desarrollo de un proceso de alfabetización (Santoyo y Arellano, 1997) que hoy en día son retomados en la era digital por los profesores indígenas.

Los recursos digitales en lenguas originarias, según Careaga (2011) se localizan en un Repositorio llamado "La Casa de la Enseñanza y el Aprendizaje" (http:// reddesac.wixsite.com/reddes). Son productos elaborados por los propios docentes hablantes de lenguas originarias del país, para los niveles de Educación Básica y Media Superior. Estos materiales se construyeron a partir del proyecto denominado Red de Talleres de Producción Digital de Contenido Educativo y Cultural (RTPD) en el estado de Veracruz, México. También este proyecto se encarga de capacitar a docentes de lenguas indígenas en el diseño y elaboración de Objetos Digitales Educativos (ODE), para las escuelas de sus comunidades, utilizando software libre, lo que constituye un ejercicio moderno de aplicación de la política digital en México y en Chiapas. De la misma forma, las publicaciones multimedia, en formato de disco compacto, creadas por la Coordinación General de Educación Intercultural y Bilingüe (CGEIB, 2016) como apoyo didáctico a los programas de las asignaturas de lengua y cultura para la educación secundaria en seis lenguas indígenas denominadas como: Jkuxlejaltik-Tsotsil (La totalidad de nuestra vida), Jkuxlejaltik ta balumilal-Tseltal (La totalidad de nuestra vida en el mundo), K-kuxtal yóok'ol kaab-Maya (Nuestra existencia en el universo), Lidzlyu'yu' ga bdchinto-Zapoteco (El mundo: tierra donde nacimos), Ndia takuyo nuu nuyiví-Mixteco (Nuestra vida en el mundo), Semanauak naua olinyolistli-Náhuatl (La totalidad de la vida en movimiento en el mundo náhuatl). Estos programas pretenden auxiliar a los jóvenes estudiantes de educación secundaria, en la generación de elementos de reflexión sobre la riqueza de la lengua y la cultura. Estas experiencias educativas son un avance sustancial en México para el desarrollo de la educación digital en las poblaciones indígenas.

Es evidente que los recursos digitales sirven de ayuda a los estudiantes como herramientas cognitivas en la vida escolar, tal es el caso del objeto digital, su intención pedagógica es coadyuvar en la enseñanza y aprendizaje basada en computadoras: que contienen información almacenada en formato digital que puede ser reutilizado (Wiley, 2002) para apoyar el aprendizaje de la lengua Ch'ol. Expertos como Mason, Weller \& Pegler (2003) definen al objeto digital como una pieza digital de material de aprendizaje que direcciona un tema claramente identificable o el proceso de transmisión de información para el aprendizaje, con el potencial de ser reutilizado en diferentes contextos educativos y sociales. Por su

7 Organismo norteamericano, de carácter antropológico y lingüístico, con carácter religioso (protestantismo norteamericano), que desde 1948 ha trabajado en territorio mexicano, formando gramáticas, léxicos y trabajos antropológicos sobre las culturas indígenas de México. 
parte Polsani (2003) también señala que "un objeto de aprendizaje es una unidad de contenido de aprendizaje independiente y autónoma que está predispuesta a la reutilización en múltiples contextos de instrucción” (párr. 20). Los contenidos multimedia son conjuntos de archivos de textos, ilustraciones, videos, fotografías, animaciones y otros tipos de recursos digitales (mapas, cápsulas de audio, etcétera) que ayudan a mejorar el aprendizaje de los estudiantes indígenas (González, 2005).

La pertinencia de planificar y estructurar nuevas herramientas digitales acordes al contexto con actividades interactivas, es un reto que contribuye en el proceso de enseñanza-aprendizaje de la lengua originaria, de manera eficaz, como el caso que nos ocupa de la lengua Ch'ol en esta investigación. En educación media superior y superior la incorporación de las TIC es una necesidad para articular los planes y programas universitarios, los cuales se traducen solamente en dotación y equipamiento de computadoras y señal de internet; dejando a un lado las acciones concretas de mediación didáctica que favorecen la formación de los estudiantes (Ramírez, Casillas y Contreras, 2014a). Las universidades, en México, han adoptado el uso de programas especializados (Autocad, Photoshop, CorelDraw, entre otros) para la ejecución de proyectos como herramientas para la formación de los estudiantes en carreras técnicas como ingeniería, arquitectura, diseño gráfico, por mencionar algunos. Las carreras distintas a estas (pedagogía, ciencias administrativas, etcétera) se enfocan al uso de programas informáticos populares como es el procesamiento de palabras, la manipulación de un conjunto de datos numéricos en hojas de cálculo y la administración de presentaciones electrónicas para la formación digital (Ramírez et al., 2014b).

Las TIC se han convertido en un instrumento de mediación para la enseñanza de idiomas que ha impulsado una industria de tecnologías, que ayudan a los docentes mediante el suministro de materiales didácticos complementarios como los libros de texto y materiales multimedia con "video, audio y discos compactos con actividades, programas interactivos y acceso a sitios de Internet" (Ramírez et al., 2014, p. 125c) que son necesarios para favorecer la enseñanza de lenguas, a través, de la interactividad y manipulación de estos artefactos digitales, desde la perspectiva del modelo intercultural en las universidades interculturales del país.

\section{Metodología}

a) El contexto sociocultural de la investigación

La UNICH fue el espacio donde se llevaron a cabo las actividades de investigación sobre la enseñanza de la lengua Ch'ol en el año 2018-2019, en un ambiente de 
diversidad lingüística y cultural, a partir del diseño tecnopedagógico de un objeto digital que se denominó Lakty'añ $\mathrm{Ch}^{\prime} \mathrm{l}^{8}$ (nuestra lengua). Los participantes tuvieron como intención profesional aprender la lengua Ch'ol. El grupo se conformó con treinta (30) estudiantes, de los cuales diecinueve (19) alumnos fueron de quinto semestre y once (11) de sexto semestre, que cursaron las licenciaturas de Lengua y Cultura, Desarrollo Sustentable, Turismo Alternativo y Comunicación Intercultural. De ese total, veintiocho (28) son hablantes del español, uno (1) de lengua Ch'ol y uno (1) de la lengua Tsotsil de la región de los Altos de Chiapas. Además, veintitrés (23) estudiantes señalaron que radican en la ciudad de San Cristóbal de Las Casas, Chiapas.9 También cuatro (4) estudiantes son originarios del municipio de Villa Flores, uno (1) de Acala, uno (1) de Ocosingo y uno (1) de Salto de Agua, Chiapas. Todos los estudiantes son originarios de las regiones culturales y lingüísticas de Chiapas, donde la cosmovisión indígena está presente y provienen de familias campesinas y de empleados eventuales poco remunerados económicamente que sobreviven en condiciones de desigualdad social y educativa.

Asimismo, la UNICH se fundó en el año 2004 en la coyuntura política y étnica del conflicto armado zapatista de 1994, para desarrollar actividades de educación superior bajo el modelo intercultural. Actualmente, la institución se localiza en la zona norte oriente de la ciudad de San Cristóbal de Las Casas, Chiapas, México, en la región de los Altos de Chiapas donde mayoritariamente habita población Tseltal y Tsotsil.

b) Enfoque metodológico

La investigación es de corte cualitativo. Se conciben los procesos de cambio social destacando la comprensión y descripción de los actores educativos en la UNICH, en el período 2018-2019. Este paradigma de investigación es inductivo, flexible y holístico; ya que piensa a los grupos humanos y educativos como un todo, porque no se reducen a variables de medición (Taylor y Bogdan, 1984). La investigación explora y reflexiona el objeto de estudio de orden tecnopedagógico desde el contexto específico de los estudiantes, a la vez que el investigador y los

\footnotetext{
8 El objeto digital Lakty'añ Ch'ol contiene diseño de actividades pedagógicas de la lengua Ch'ol. Esta innovación aproxima al usuario a la cultura mayense de Chiapas. Su contenido implica el desarrollo autónomo de actividades donde se pretende dar a conocer y aprender frases de uso cotidiano, numeraciones, conjugaciones de verbos, nombres de algunos animales tanto domésticos como silvestres. Además de la nominación de frutas, verduras, partes del cuerpo humano, nombres de vestimenta tanto para el hombre como para la mujer y otros vocablos de la lengua Ch'ol. Asimismo, se complementa con aspectos relacionadas al desarrollo de la fonética, léxico, sintáctico, semántico y pragmático.

9 Todos los nombres referidos son municipios de estado de Chiapas, México.
} 
participantes interactúan entre sí para obtener los datos con el interés de resolver diversas situaciones y problemas que ocurren en la práctica docente (McKernan, 2008; Sandin, 2003; Elliot, 2005), en particular la enseñanza y aprendizaje de la lengua Ch'ol. Entre las técnicas de recolección de datos se encuentran la observación como un método de trabajo de campo que consiste en valorar y comprender el contexto social de la universidad (Latorre, 2005a). También se aplicó la entrevista semiestructurada como medio para obtener los puntos de vista de manera abierta de los sujetos (Flick, 2007).

c) El trabajo de investigación documental

Se consultaron fuentes bibliográficas y hemerográficas que se localizaron en bibliotecas virtuales y presenciales de la Universidad Autónoma de Chiapas (UNACH), Universidad Intercultural de Chiapas (UNICH) e instituciones de gobierno estatal y federal. Los documentos analizados son de orden teórico sobre la enseñanza de lenguas mediadas por el objeto digital, entre los cuales se destacan las estrategias didácticas (Santacruz, Dávila y Lavander, 2018a) que permitieron abordar la lengua Ch'ol, el desarrollo de las competencias digitales (Valverde, 2012), las competencias comunicativas (Santos, 2015) para el aprendizaje de la lengua Ch'ol, así como las implicaciones psicolingüísticas (Arroyo, 1992) en la adquisición de las habilidades comunicativas del Ch’ol. Posteriormente, la información documental se procesó en fichas de trabajo que fueron contenidas para ser analizadas y categorizadas (Rojas, 2011).

d) La obtención de información a partir de la aplicación del objeto digital

La información empírica se obtuvo del trabajo de observación de la práctica suscitada en el aula donde se localiza a 30 estudiantes que estuveron inmiscuidos en el desarrollo del objeto digital sobre la enseñanza-aprendizaje oral y escrito de la lengua Ch'ol. Dicho proceso implicó la documentación de los problemas de organización curricular, el acceso a las competencias digitales tanto de maestros como de alumnos, las actitudes lingüísticas frente al acceso de la tecnología, la metodología de trabajo del profesor mediatizadas por la competencia digital, los esfuerzos motivacionales y colaborativos de los estudiantes para desarrollar la escritura y lectura del Ch'ol, bajo el modelo intercultural. La observación se enfocó en conocer las distintas dimensiones sociopolíticas y pedagógicas de aprendizaje de estudiantes y profesores, quienes se comprometieron en el desarrollo de la lengua Ch'ol. De igual forma se registraron las características de la secuencia didáctica, esto le sirvió al profesor para planificar los diversos aspectos metodológicos implicados en la aplicación del objeto digital Lakty’añ Ch'ol para la enseñanza de la lengua Ch'ol. La información obtenida de las observaciones en 
distintos momentos y períodos de trabajo en la UNICH se registró en el Diario del Profesor (Latorre, 2005b).

También se diseñó una guía de entrevista semiestructurada que se aplicó a 30 alumnos al término del semestre, quienes decidieron de manera voluntaria por un tiempo de 25 minutos, plasmar sus juicios y comentarios inherentes al desarrollo del objeto digital sobre el aprendizaje del Ch'ol en la UNICH. El instrumento tuvo dos apartados. El primero se relaciona con los datos de identificación: edad, procedencia étnica, formación académica y lingüística de los estudiantes. El segundo apartado estuvo constituido por preguntas a través de las cuales los alumnos de forma espontánea plasmaron sus ideas y percepciones en torno a la metodología de aprendizaje a partir de las herramientas tecnológicas, el uso del laboratorio de idioma, la influencia de los recursos digitales en el aprendizaje del Ch'ol, los tipos de actividades en el aula y los contenidos que les generaron mayor motivación o gusto aprender, la capacidad de procesar información con los contenidos educativos, la orientación de escribir, de redactar hasta producir textos en Ch'ol y el trabajo colaborativo, además de la disposición actitudinal en la construcción de la escritura del Ch'ol.

\section{e) La categorización y sistematización de la información}

La información obtenida de documentos electrónicos e impresos fue analizada a partir del marco teórico sobre el objeto digital de la enseñanza-aprendizaje de la lengua Ch'ol, así como la información que se obtuvo de las entrevistas semiestructuradas y las observaciones contenidas en el Diario del Profesor. Dicha información fue transcrita en el programa de Microsoft Word 2016, a través del cual se procesaron y analizaron las relaciones tecnoeducativas a partir de la aplicación del objeto digital. Con esta información sistematizada, se hicieron los procesos de inferencia y deducción de orden metodológico que se convirtieron en las interpretaciones de las condiciones del desarrollo del objeto digital del aprendizaje del Ch'ol, a partir del marco teórico construido (Abero, Berardi, Capocasale, Montejo y Soriano, 2015). Derivado de este proceso metodológico y teórico se obtuvieron los hallazgos que permitieron cumplir con la investigación del aprendizaje del Ch'ol bajo el modelo intercultural en la UNICH, que finalmente, dio pauta al desarrollo de la descripción e interpretación de los datos duros a partir de la fundamentación teórica que se plasmó en la investigación. 


\section{Resultados y discusión}

El aprendizaje de la lengua Ch'ol entre los estudiantes

La comunicación entre estudiantes se realiza en español, en el aula y fuera de ella. Se empleó esta lengua como una "lengua común", en función del aprendizaje del Ch'ol. Es una constante social y escolar que se logra observar. La enseñanza del Ch'ol a través del objeto digital educativo marcó un precedente importante en el aula porque motivó el trabajo grupal e individual de los alumnos, quieres mostraron sus habilidades de lectura y escritura en la lengua Ch'ol. Los temas abordados referentes a la cultura y cosmovisión Ch'ol, se situaron como unidades didácticas que permitieron desarrollar las destrezas en la producción oral y descripción de las características de la indumentaria, así como redacción de textos cortos relacionados con la fiesta tradicional, de acuerdo con el programa de estudio de la institución del área de lenguas para que emergiera como una dimensión de aprendizaje relevante de la vida escolar de los estudiantes (Muñoz y Villar, 2009). Por tanto, las evidencias identificadas entre los estudiantes son positivas en el acceso a la lengua Ch'ol, porque se percibió que reconocieron su identidad y valoraron el patrimonio cultural de su entorno a través de cambios de actitud y la adquisición de la lengua indígena en el aula al utilizar la tecnología diseñada como objeto digital Lakty'añ Ch'ol.

De esta manera, en el salón de clases los dispositivos como el cañón, la laptop y sobre todo el objeto digital Lakty’añ Ch'ol que se diseñó y aplicó, generó una actitud positiva y emocional en la clase de lengua Ch'ol. Por eso, el recurso digital de esta naturaleza engloba a todo el entorno de comunicación en un solo sistema de medios, tales como las imágenes que pueden presentarse de manera estática o en movimiento, analógicas o digitales, es decir, el "uso combinado de diferentes medios de comunicación: texto, imagen, sonido, animación y video" (Belloch, 2012, p. 1), facilitó que los 30 alumnos pudieran aprender la lengua Ch'ol de manera sustancial, pero con ciertas debilidades gramaticales. Las percepciones y motivaciones que se crean en los estudiantes al presentar los contenidos curriculares de forma interactiva, cobró sentido e indicaron que hubo pertinencia de los elementos pedagógicos utilizados como las estrategias didácticas empleadas sobre la lengua Ch'ol (Santacruz et al., 2018b). Con esta actividad se logró establecer un trabajo a la par con las tendencias tecnológicas actuales, que potencian la difusión y comunicación entre los alumnos, a través de los dispositivos electrónicos. 
No obstante, los alumnos mencionaron haber utilizado recursos multimedia en otras clases delengua, se siguen sorprendiendo de la variación de las presentaciones de las actividades de aprendizaje de la lengua Ch'ol. También señalaron no haber conocido en sus experiencias de vida escolar el manejo de un objeto digital, como medio de construcción del pensamiento de lengua escrita del Ch'ol. En ese sentido, al usar los medios digitales en el aula se percibió el entusiasmo de los estudiantes en apropiarse de la lengua Ch'ol, a partir de juegos interactivos que se les ofrecen en el objeto digital Lakty’añ Ch’ol. Además, con el apoyo de imágenes auténticas de la tecnología les ayudan a recordar conceptos que los sitúan en el contexto social de los hablantes, esto induce a pensar que se apega a los intereses y expectativas de los alumnos. Así pues, uno de los requisitos del aprendizaje es la motivación que tiene el estudiante frente al objeto de aprendizaje, como lo es la lengua Ch'ol y los nuevos materiales que van a ser aprendidos, los cuales deben ser potencialmente significativos (García, 1990).

En la actualidad, las teorías pedagógicas, de orden bilingüe, señalan diversas formas de obtener información y conocimiento entre los estudiantes y la lengua, por lo que el objeto digital se localizó como una expresión de uso individual y social tecnopedagógico (Coll, Mauri, Onrubia, 2008) que avanza en el desarrollo del conocimiento educativo intercultural de producción oral, de lectura y escritura entre los 30 estudiantes. La enseñanza que se produjo en la práctica en el aula intercultural implicó innovar, por medio del uso de la tecnología el trabajo del asesor de los cursos de la lengua Ch'ol; lo que derivó en un aprendizaje relevante en los estudiantes y sus modos de interacción, el respeto mutuo entre las culturas, los valores y tradiciones (Walsh, 2005) que se tradujo como la competencia comunicativa exigida en el mundo globalizado.

Además, en este escenario de aprendizaje sobresale el manejo y uso de sinónimos, antónimos y tiempos adverbiales; lo que permite constatar el fin de las estrategias didácticas empleadas, puesto que fortalecieron las habilidades auditivas, orales y escritas de los participantes. En ese proceso, los alumnos utilizaron diferentes imágenes y videoclips apegados al tema y al contexto de la cultura Ch'ol, donde se evidenció la apropiación del lenguaje escrito, como capacidad de expresión oral y escrita de manera normada con deficiencias gramaticales como lo señalan las reglas normadas del Ch'ol (INALI, 2011b). Sin embargo, un buen manejo de la lengua se verá a largo plazo, porque los estudiantes denotan serias dificultades por escribir y leer de manera organizada la lengua Ch'ol.

Aunado a lo anterior, se comenzó con el manejo de léxico para luego transitar de manera paulatina hacia la construcción de oraciones cortas propuestas en el objeto digital que dio resultados favorables. Las actividades fueron producciones 
escritas de acuerdo con la imagen proporcionada, por ejemplo, se'btyo tyaloñ ijk'äl (mañana vengo temprano), tyi xiñk'iñil majlel kjap ksa' (a medio día voy a tomar mi pozol), samoñix wolix tyi ik'añ (me voy ya se está atardeciendo); actividad que encauzó un aprendizaje significativo y se deduce que el uso interactivo de los medios digitales constituye una posibilidad de propiciar actividades didácticas y recreativas de la lengua Ch’ol. Además, aprendieron a relacionar las palabras con las imágenes y a completar las oraciones con las palabras que hacían falta.

Otra de las evidencias localizadas en este escenario formativo de los estudiantes, demostró que las tecnologías ayudan a los alumnos a aprender la escritura de un modo más efectivo, en el aula de la UNICH. Este juicio se relaciona con aportaciones de estudios que señalan acerca del contexto socio-comunicativo digital del siglo XXI, en las universidades, es un proceso de enfrentamiento de manera positiva de los estudiantes, ante las necesidades comunicativas en la interacción social a partir de foros, los blogs, wikis y redes sociales (Zayas, 2011) para dominar el aprendizaje del Ch'ol. Esta práctica implicó que los actores del proceso formativo hicieran a un lado de manera razonada y equilibrada sus actividades regulares, lo que tradicionalmente se ha venido empleando como la pizarra, tiza, libros en papel, entre otros; se dió paso a que combinaran con el uso de las nuevas tecnologías, siendo el ordenador, la internet, las pizarras digitales (Juan, 2012) un punto clave de transformación escolar, en la UNICH. Esto hizo que se adoptara un modelo de instrucción en el que se abona al uso de las TIC, mismo que conllevó a los estudiantes a ser participativos, indagadores y capaces de construir conocimientos de forma colaborativas (Sunkel et al., 2014b). Esta visión de la comunicación digitalizada tanto del estudiante, como del profesor puede mejorar la formación de la lengua originaria, por medio de la creación de sus propios materiales didácticos. Esto nos lleva a pensar que la integración de la tecnología en el ámbito educativo intercultural genera desafíos en diferentes áreas de la enseñanza, transformando la comunicación, el tratamiento de la información y las relaciones interpersonales, como ocurre en la UNICH. En el ámbito de la interculturalidad, la política educativa señala la necesidad de desarrollar competencias digitales y lingüísticas en el proceso de revaloración y resignificación de la cultura indígena Ch’ol (Mato, 2008).

De acuerdo con Sunkel et al. (2014c) las competencias digitales asumidas como construcción de la lengua escrita de manera digital por los estudiantes, ocurrieron en la elaboración de sus bitácoras de trabajo, conocidas también como weblogs; lo que permitió que los estudiantes redactaran en una página de Moodle adaptado por el docente de la lengua. Dicho weblog fue utilizado de manera entusiasta para crear comunidades de conocimiento, fomentar la reflexión y aportar información sobre asuntos de interés mutuo entre los estudiantes de quinto y sexto semestre 
que participaron activamente (Luzardo, s.f). Esta actividad registrada como resultado de la aplicación del objeto digital denota un potencial de capacidades tecnológicas en el uso de los nuevos escenarios digitales para que los estudiantes puedan crear sus propias estrategias de apropiación de información, y administren adecuadamente sus tiempos y la manera de clasificar la información que son habilidades metacognitivas en el fortalecimiento de la competencia comunicativa del Ch'ol.

Las competencias digitales (García, De león y Orozco, 2016) de los estudiantes, llevadas a cabo en distintas secciones y de actividades propuestas, sin la intervención del docente, generaron un desarrollo de las habilidades de navegación en una plataforma educativa de manera autónoma; donde se realizan las actividades didácticas de la lengua Ch'ol. Esto indica que el proceso digital en los estudiantes tiene capacidades cognitivas en el uso de las TIC. En efecto, esto es la capacidad de gestionar el conocimiento tecnopedagógico mediante la interacción de sitios de Internet para que cuando realicen actividades en clase con el objeto digital educativo no se les dificulte el dominio de la lengua Ch'ol a los estudiantes. Los saberes digitales entre los estudiantes del Ch'ol trajo consigo que se incorpore el objeto digital en la plataforma educativo Moodle donde exploraron, navegaron y conocieron el aspecto idiomático del Ch'ol. De igual modo, se enfrentaron los alumnos a un proceso de adaptación y aceptación que los motivó constantemente a aprender la lengua; lo que generó, a su vez, cambios cognitivos mediante la interacción digital. Esto nos lleva a pensar que se dio un proceso de asimilación en la adquisición del conocimiento sobre la lengua materna Ch'ol (Ausubel, 1976). De esta manera, la pertinencia de las actividades incorporadas en el recurso digital implicó interactividad y usabilidad, es decir, promovió la participación activa de los usuarios (Salgado y Villavicencio, 2010).

Asimismo, el uso digital también sirvió para retroalimentar los conocimientos adquiridos por parte de los estudiantes, con las unidades temáticas, relacionadas con la secuencia didáctica que determinó el proceso de avance y la valoración de la adquisición del conocimiento de la lengua $C h$ 'ol, a través de la interactividad con el objeto digital.

El uso de fotos de las fiestas tradicionales más representativas de la cultura Ch'ol contextualizadas de esta manera, implicó una situación comunicativa favorable en la enseñanza-aprendizaje del Ch’ol. Los materiales auténticos en el ámbito digital son aquellos que han sido creados con una función comunicativa y social 
como las revistas, periódicos, cuentos, folletos, realia ${ }^{10}$, internet (Fernández, 2008), entre otros que posibilitaron la enseñanza de la lengua maya Ch'ol. Estas herramientas son esenciales en el aprendizaje de un idioma, ya que pueden ser adaptados o modificados con fines tecnopedagógicos para los no nativo-hablantes como ocurrió con la enseñanza del Ch’ol. Esta experiencia de trabajo didáctico con los estudiantes, les facilitó comprender y recordar los vocablos de la lengua Ch'ol. Los propios participantes señalan tener una mejor apropiación y retención de la información de manera significativa como parte de la implicación del objeto digital en la UNICH.

\section{Conclusiones}

A través de la investigación efectuada sobre el diseño y aplicación de un objeto digital educativo, se logró facilitar de manera dinámica el aprendizaje de la lengua Ch'ol como parte de un mecanismo de transformación de la práctica docente intercultural, que incidió en 30 estudiantes de diversas procedencias lingüísticas, en la Universidad Intercultural de Chiapas, México. Dicho recurso digital fue de gran importancia en el procesamiento de información lingüística; ya que influyó en la activación psicológica del proceso de internalización de significados escolares, a través, de la interactividad tecnopedagógica con las actividades apegadas al contexto de la lengua Ch'ol, tomando en cuenta los contenidos del programa de lenguas originarias que diseñó el Centro de Revitalización y Estudios de las Lenguas de la Universidad Intercultural de Chiapas.

Derivado de esta aplicación digital los estudiantes se interesaron y motivaron por conocer de manera práctica el objeto digital de aprendizaje, porque les generó una mayor motivación, y centraron su atención en desarrollar los trabajos didácticos de manera organizada y colegiada sobre la lengua Ch'ol. Este esfuerzo de crear y proponer un recurso tecnopedagógico produce un anclaje y andamiaje cognitivo que aporta un mayor potencial para la adquisición de la lengua entre los estudiantes, es decir, se evidencia que de manera objetiva la interacción psicológica con el recurso didáctico para el aprendizaje de la lengua Ch'ol, mediatizada por el objeto digital, adquiere un sistema de apropiación de los conceptos, imágenes, códigos y normas que incorporados al ámbito de la competencia comunicativa. Son conocimientos que trascienden la experiencia social universitaria e intercultural en Chiapas.

\footnotetext{
10 Se deriva de la palabra real, la cual proviene del latín de la palabra reãlis, que traducido en castellano es "real, verdadero". Entonces se puede deducir que es cualquier objeto físico real y verdadero introducido en el aula como material con carácter didáctico, es decir, que sirve para dar significado al contenido que se desarrolla durante la enseñanza (Prieto, 2018).
} 
Es importante crear las competencias digitales convertidas a expresiones comunicativas del Ch'ol que presentaron los estudiantes en un contexto de desigualdad social en este siglo XXI, en la región de los Altos de Chiapas, empobrecidas por las políticas neoliberales, para facilitar el acceso a los estudiantes indígenas de las Tecnologías de la Información y Comunicación en el dominio de las lenguas maternas indígenas. Asimismo, el entusiasmo de los estudiantes y profesores sobre el acceso a las plataformas virtuales y educativas implicó la construcción de nuevos conocimientos del Ch’ol basados en la reflexión crítica y analítica, en una coyuntura política como la que experimenta México, bajo la denominada Cuarta Transformación Social del Gobierno Federal, sobre los Pueblos amerindios en Chiapas. Dicho cambio político, ha puesto la mirada en planes sociales, recuperación de conocimientos ancestrales y en específico, en el reconocimiento del valor lingüístico de México.

La intermediación de la enseñanza de la lengua a través del objeto digital promovió el aprendizaje tanto individual y grupal, lo que induce a pensar que de ser estudiantes receptores pasivos transitaron al de un aprendiz competente del Ch'ol, puesto que mostraron actitudes de mayor compromiso escolar. Los contenidos curriculares e interculturales que se incorporaron en el objeto digital fueron parte de la gramática del Ch'ol. Transitaron en aprendizajes de oraciones gramaticales como lo establece la función comunicativa y social de la propia lengua indígena. En consecuencia, el objeto digital educativo es un aporte para la lengua Ch'ol, con la cual se espera pueda ser utilizada como recurso de enseñanza-aprendizaje de esta lengua y de otras que se encuentra subalterizadas y excluidas por el entorno local, nacional y global. Finalmente, se espera que esta experiencia desarrollada pueda ser motivo de otros estudios que permitan redefinir una política educativa digital e intercultural, para los pueblos indígenas de México y Chiapas.

\section{Referencias}

Abero, L., Berardi, L., Capocasale, A., Montejo, S. G. y Soriano, R. R. (2015). Investigación educativa. Abriendo puertas al conocimiento. Uruguay: CLACSO.

Aguirre, M. M. (2015). Comunidades de aprendizaje: retos para la ampliación del impacto social de las Universidades Interculturales. Documento de trabajo núm. 186. Recuperado de http:/www.rniu.buap.mx/infoRNIU/ abr15/2/bol_cesop_documento-trabajo-n186.pdf

Arroyo, F. V. (1992). Psicolingüística. España: Morata.

Ausubel, D. P. (1976). Psicología Educativa: Un punto de vista cognoscitivo. México: Trillas. 
Barreto, C. R. y Diazgranados, F. I. (Dirs). (2017). Las TIC en la educación superior: Experiencias de innovación. Colombia: Universidad del Norte.

Belloch, C. (2012). Aplicaciones multimedia. Aplicaciones multimedia interactivas. Recuperado de https:/www.uv.es/bellochc/logopedia/ NRTLogo4.pdf.

Careaga, A. A. (2011). Temas selectos de producción multimedia. Red de Talleres de Producción Digital de Contenido Educativo y Cultural. Veracruz, México: REDDES-DGEI-COVECYT.

Castellanos, A. I. R. (2014). Pedagogía y calidad educativa en la era digital y global. Colombia: ECOE.

Castells, M. (2000). La era de la información: economía, sociedad y cultura. Vol. 1. La sociedad red. México: Siglo XXI.

Coll, C., Mauri, T. y Onrubia, J. (2008). La utilización de las tecnologías de la información y la comunicación en la educación: Del diseño tecnopedagógico a las prácticas de uso. En, C. Coll y C. Monereo (Eds), Psicología de la educación virtual (pp. 74-103). Madrid: Morata.

Coordinación General de Educación Intercultural y Bilingüe (2016). Colección: propuestas educativas en EIB. Recuperado de https://eib.sep.gob.mx/wpcontent/uploads/2017/01/Propuestas-educativas.pdf.

Cruz, C. S. R. (2009). Revitalización y fortalecimiento lingüístico: La normalización de los sistemas de escritura de algunas lenguas indígenas de Chiapas. Recuperado de https://www.ailla.utexas.org/sites/default/files/ documents/CruzGomez_CILLA_IV.pdf.

Elliott, J. (2005). El cambio educativo desde la investigación-acción. Madrid: Morata.

Fábregas, P.A. (2008). La experiencia de la Universidad Intercultural de Chiapas (México). En, D. Mato (Coord.), Diversidad cultural e interculturalidad en educación superior. Experiencias en América Latina (pp. 339-348). Caracas: Instituto Internacional para la Educación Superior en América Latina y el Caribe (IESALC), UNESCO.

Fajardo, I., Villalta, E. y Salmerón, L. (2016). ¿Son realmente tan buenos los nativos digitales?: relación entre las habilidades digitales y la lectura digital. Anales de psicología, 32(1), 89-97. Recuperado de http://scielo.isciii. es/pdf/ap/v32n1/psicologia_evolutiva4.pdf.

Fernández, B. J. A. (2008). “Authentic Materials”. Innovación y experiencias educativas. Recuperado de https://archivos.csif.es/archivos/andalucia/ ensenanza/revistas/csicsif/revista/pdf/

Numero_8/ALBERTO_ FERNANDEZ_1.pdf. 
Flick, U. (2007). Introducción a la investigación cualitativa. Madrid: Morata.

García, J. F., De León, T. y Orozco, E. (Eds.). (2016). Desarrollo de competencias para el siglo 21. Miami: Humboldt International University.

García, M. J. A. (1990). Aprendizaje por descubrimiento frente a aprendizaje por recepción: la teoría del aprendizaje verbal significativo. En, C. Coll, J. Palacios y A. Marchesi (Comp.), Desarrollo psicológico y educación II: psicología de la educación (pp. 81-92). Madrid: Alianza.

González, A. M. (2005). Cómo desarrollar contenidos para la formación online basados en Objetos de Aprendizaje. Revista de Educación a Distancia, Monográfico III. Recuperado de http://revistas.um.es/red/ article/view/24631/23951.

Hernández, I. y Calcagno, S. (2003). Los pueblos indígenas y la sociedad de la información. Revista Argentina de Sociología, 1(1), 110-143. Recuperado de https://www.redalyc.org/pdf/269/26900108.pdf.

Ianni, O. (2006). Teorías de la globalización. México: Siglo XXI.

Instituto Nacional de Estadística y Geografía (2015). Lenguas indígenas en México y hablantes (de 3 años y más) al 2015. Encuesta intercensal. Recuperado de http://cuentame.inegi.org.mx/ hipertexto/todas_lenguas. htm.

Instituto Nacional de Lenguas Indígenas (2011). CH’ol: Ityoj ts'ijbuntyel lakty’añ CH'ol. CH'ol: Norma de escritura de la lengua CH'ol. México: INALI, Chiapas: Gobierno del Estado de Chiapas, Secretaría de Educación, Universidad Intercultural de Chiapas.

Jiménez, E. J. y Gutiérrez, J. G. (2008). Säkläji’b ty’añ ch’ol. Tuxtla Gutiérrez, Chiapas, México: Secretaría de Educación.

Juan, R. A. D. (2012). El uso de las nuevas tecnologías en el aula de lenguas extranjeras. Tonos. Revista electrónica de estudios filológicos. Recuperado de https:/www.um.es/tonosdigital/znum22/secciones/tintero-6-uso_de_ las_nuevas_tecnologias.htm.

Latorre, A. (2005). La investigación-acción. Conocer y cambiar la práctica educativa. España: GRAO.

López, R. L. y Gutiérrez, J. G. (2002). Vocabulario ch'ol-español. Tuxtla Gutiérrez, Chiapas, México: Servicios Educativos para Chiapas.

Luzardo, M. H. (s.f). La evaluación alternativa en el enfoque tecnológico. Revista de tecnología de información y comunicación en educación. Recuperado de http://servicio.bc.uc.edu.ve/educacion/eduweb/Vol3n2/ art10.pdf. 
Mason, R., Weller, M. \& Pegler, C. (2003). Learning in the Connected Economy. Londres: Open University.

Mato, D. (Coord.) (2008). Diversidad cultural e interculturalidad en educación superior. Experiencias en América Latina. Caracas: Instituto Internacional para la Educación Superior en América Latina y el Caribe (IESALC), UNESCO.

McKernan, J. (2008). Investigación-acción y curriculum. Madrid: Morata.

Montejo, L. B., López, L. R., Guzmán, G. J., Jiménez, J. E. y Martínez, L. E. (1999). Ña'alty’añ Ch’ol. Tuxtla Gutiérrez, Chiapas, México: Servicios Educativos para Chiapas.

Muñoz, M. L. C. y Villar, L. S. (2009). Universidad Intercultural: modelo educativo. México: CGEIB-SEP.

Polsani, P. (2003). Uso y abuso de objetos de aprendizaje reutilizables. Revista de información digital, 3(4). Recuperado de https://journals.tdl.org/jodi/ index.php/jodi/article/view/89/88.

Prieto, A. S. M. (2018). El uso de realia y material auténtico en la enseñanza de lengua extranjera en educación primaria (Trabajo fin de grado). Logroño: Universidad de la Rioja.

Ramírez, M. A., Casillas, A. M. A. y Contreras, A. C. C. (2014). La incorporación de las TIC a la enseñanza universitaria de los idiomas. Debate Universitario, 3(5), 123-138. Recuperado de http://portalreviscien.uai.edu. ar/OjS/index.php/debate-universitario/article/view/20.

Rojas, S. R. (2011). Guía para realizar investigaciones sociales. México: Plaza y Valdés.

Salgado, A. E. y Villavicencio, Z. F. (2010). Materiales multimedia en contextos de diversidad lingüística y cultural. México, D.F.: Centro de Investigaciones y Estudios Superiores en Antropología Social (CIESAS).

Sandin, M. P. (2003). Investigación cualitativa en Educación. Fundamentos y Tradiciones. Madrid: McGraw-Hill.

Santacruz, E. H., Dávila, G. C. P. y Lavander, A. P. Q. (2018). Recursos digitales en la enseñanza y aprendizaje de una segunda lengua. En, N. A. Cortez, K. McBride y E. R. Esparza (Coords.), A enseñar: una guía para los maestros de idiomas (pp. 133-147). México: Pearson.

Santos, G. S. (2015). La enseñanza de lenguas indígenas a adultos. Formación de profesores hablantes de lenguas indígenas. Tepic, Nayarit: Universidad Autónoma de Nayarit. 
Santoyo, R. M. y Arellano, S. J. (1997). El instituto lingüístico de verano y el protestantismo en México. Convergencia. Revista de ciencias sociales, (14), 231-262.

Sunkel, G., Trucco, D. y Espejo, A. (2014). La integración de las tecnologías digitales en las escuelas de América Latina y el Caribe. Una mirada multidimensional. Santiago de Chile: Naciones Unidas/CEPAL.

Taylor, S. J. y Bogdan, R. (1984). Introducción a los métodos cualitativos de investigación. La búsqueda de significados. Barcelona: Paidós Ibérica.

Valverde, B. J. (2012). Estrategias educativas para el desarrollo de la competencia digital. En, Y. Sandoval, A. Arenas, E. López, J. Cabero y J. I. Aguaded (Coords.), Las tecnologías de la información en contextos educativos: nuevos escenarios de aprendizaje (pp. 55-68). Santiago de Cali: Universidad Santiago de Cali.

Walsh, C. (2005). La interculturalidad en la educación. Perú: Ministerio de Educación.

Wiley, D. A. (2002). Connecting learning objects to instructional design theory: A definition, a metaphor, and a taxonomy. En, D. A. Wiley (Ed.), The Instructional Use of Learning Objects (pp. 4-23). Bloomington, Indiana: Agency for Instructional Technology and Association for Educational Communications \& Technology.

Zayas, F. (2011). Tecnologías de la Información y la comunicación y enseñanza de la lengua y de la literatura. En, U. Ruiz (Coord.), Didáctica de la lengua castellana y la literatura (pp. 139-165. Barcelona: Graó. 